American Journal of Animal and Veterinary Sciences 4 (4): 80-84, 2009

ISSN 1557-4555

(C) 2009 Science Publications

\title{
Radiographic Evaluations of the Tetra-Calcium Phosphate and Diacalcium Phosphate with Bone Plate in Osseo-Integration of Bone Repair in Rabbit
}

\author{
${ }^{1}$ Davood Sharifi, ${ }^{2}$ Sarang Soroori, ${ }^{3}$ Saeed Hasaraki and ${ }^{4}$ Nazanin Jafari \\ ${ }^{1}$ Department of Surgery, Faculty of Veterinary Medicine, University of Tehran, Iran \\ ${ }^{2}$ Department of Radiology, Faculty of Veterinary Medicine, University of Tehran, Iran \\ ${ }^{3}$ Department of Materials and Energy Research, Karaj, Iran \\ ${ }^{4}$ Department of Surgery and Radiology, Faculty of Veterinary Medicine, \\ University of Tehran, Iran
}

\begin{abstract}
Problem statement: To determine the effect of the Tetra calcium phosphate and Diacalcium phosphate cement in comparison with bone plate in fracture repair in rabbit. Experimental in vivo study. A total of 18 adult male White New Zealand rabbits, weighing $3.0 \pm 0.250 \mathrm{Kg}$ and about 6 months old were used. They were fasted $4 \mathrm{~h}$ before start of experiment and were off-water even $2 \mathrm{~h}$ too. They were divided into 2 groups of bone plate (I) and cement (II) of 9 rabbits each which subsequently divided into 3 subgroups of 1(I a and II a) month and 2 (Ib and IIb)and 3 (Ic and IIc) months duration in each group. Approach: Under general anesthesia and aseptic condition the craniolateral surface of right radial was exposed and a piece of full thickness from mid-section of radial bone in length of $1 \mathrm{~cm}$ was removed using electrical bone vibrator in the all rabbit. The both ends of this bone was stabilized using mini bone plate of 4 holes in the group I, whereas prehardened cylinders of cement were implanted into rabbit radial defects in the group II rabbits. Radiographs were taken on zero days after creation of gap and on 1,2 and 3 months from each rabbit using parameters such as local changes, stabilization of implant and bone, bone formation and implant biodegradation. Results: Comparison of clinical signs in the I and II indicated that they had similar physical activity and same degree of lameness during observation period of 90 days Radiographyically keeping in view the parameters were used to evaluate the major changes revealed no sign of infection on the edges of each defect and both groups permitted stabilization of the defected bones and maintenance of correct position. The new bone formation and the implant biodegradation in the bone defects could be clearly reflected by the gradually weakened umbral on the radiographs during the whole process one repair in group I was not as perfect as those in cement or group II samples. Conclusion/Recommendations: Application of paste of tetra calcium phosphate and diacalcium phosphate indicated to have positive effect in integral formation of qualitative callus at the site of fracture and early re-organization of callus too.
\end{abstract}

Key words: Tetra-calcium phosphate, diacalcium phosphate, bone plate, radial bone, rabbit, osseo integration

\section{INTRODUCTION}

Repair of large bone is one the tough clinical problem in most of referred cases and each surgeon has his own choice of approaches too. Application of various biological implants for long bone defect repair, each possesses its own limitation in addition to immunologic response and endemic risk of grafts too ${ }^{[, 2]}$ Tetra calcium phosphate and diacalcium phosphate cement for their osteoconductive, readily osseointegrated, easily shaped and gradually degradable properties $^{[3,4]}$ are still the most commonly used cement materials to to fill up defects and gap between fractured fragments on account of their good biological properties As the results in terms of Osseo integration have not always been satisfactory under altered metabolic bone condition ${ }^{[, 2]}$ various strategies to improve Osseo integration have been specifically focused on the implant characteristic specially chemical composition $^{[3-5]}$. These may affect the cell and biochemical responses of the host bone in order to promote bone apposition through acceleration of the

Corresponding Author: Davood Sharifi, Department of Surgery, Faculty of Veterinary Medicine, P.O. Box 14155-6453, University of Tehran, Tehran, Iran Tel: + 98-21-66920035 Fax: +98-21-66933222 
chemical bonding between the new bone and implant. The aim of the present study was to compare the in vivo Osseo integration of these cement with that of bone plate in same dimensions.

\section{MATERIALS AND METHODS}

Study design: This study was performed in accordance with the University of Tehran Law on animal experimentation and this research project was approved by the Faculty of Veterinary Medicine and University of Tehran Research Council. 18 adult male New Zealand rabbits $3.0 \pm 0.250 \mathrm{Kg}$ body weight were submitted orthopedic surgery under deep and effective anaesthesia using combinations of Acepromazine Maleate (2\%) $1 \mathrm{mg} \mathrm{kgbw}^{-1}$ intramuscularly as premedication (Karon Co. Iran) and anesthesia was induced intramuscularly using $35 \mathrm{mg} \mathrm{Kgbw}^{-1}$ ketamine hydrochloride $(10 \%$ alfasan. WoerdenHolland) with combination of xylazine hydrochloride $2 \%$ using $5 \mathrm{mg} \mathrm{Kgbw}^{-1}$ (alfasan. Woerden-Holland) After securing in the supine position of each rabbit, Under general anesthesia and aseptic condition the craniolateral surface of right radial was exposed and a piece of full thickness from medial section of radial bone in length of $1 \mathrm{~cm}$ was removed using electrical bone vibrator in the all rabbit. They were divided into 2 groups of bone plate (I) and cement (II) of 9 rabbits each which subsequently divided into 3 subgroups of (I a and II a) one month and two (Ib and IIb) and three (Ic and IIc) months duration in each group. The both ends of this bone was stabilized using mini bone plate of 4 holes in the group (I) whereas the paste of tetracalcium phosphate and diacalcium phosphate used to filled the gap in the group II rabbits. Radiographs were taken on zero days after creation of gap and on 1, 2 and 3; months from each rabbit.

Antibiotics (penicillin G procaine $40000 \mathrm{IU} \mathrm{kg}^{-1}$ IM every $12 \mathrm{~h}$ ) dexamethasone $0.6 \mathrm{mg} \mathrm{Kgbw}^{-1}$ vitamin B. complex $0.2 \mathrm{mg} \mathrm{Kgbw}^{-1}$ and analgesic such as Tramadol hydrochloride ( $5 \mathrm{mg} \mathrm{Kgbw}^{-1}$ IM every $12 \mathrm{~h}$ ) were administered for 3 post-operative days.

Radiography analysis: For comparative evaluation of osseointegration of cement reaction in group II with that of bone plate used for stability of radial bone in group I, parameters such as local changes, stabilization of implant and bone, bone formation and implant biodegradation were considered. Lateral radiographs were taken on days $0,30,60,90$ post surgery using 50 $\mathrm{KVp}, 3.2 \mathrm{mAs}$ and $100 \mathrm{~cm}$ FFD. Qualitative assessment of internal callus formation, external callus formation, intercortical callus formation, osteoinduction and remaining of cement in produced gap was made in both groups of bone plate and cement.

\section{RESULTS}

No operative or postoperative complications were encountered. All of the rabbits tolerated operation well and survived until the final experimental time. No wound opening or infections were observed. Radiographyically keeping in view the parameters were used to evaluate the major changes revealed no sign of infection on the edges of each defect and both groups permitted stabilization of the defected bones and maintenance of correct position. External callus was not formed in bone plate group up to day 90 . Intercortical and internal callus was formed on day 90 in bone plate group. External and intercortical callus was not formed up to day 90 in cement group while the scaffolding of internal callus was not distinguishable in cement group due to mixing with cement. There was rounding of bone edges in some cases due to lack of steoinduction. Radiopacity and homogeneity of cement significantly reduced gradually by day 90 in cement group.

The defect repair in group I was not as perfect as those in cement or group II samples (Fig. 1-3). The new bone bone formation and the implant biodegradation in the bone defects could be clearly reflected by the gradually weakened umbral on the radiographs during the whole process bone repair in group II (Fig. 4-6).

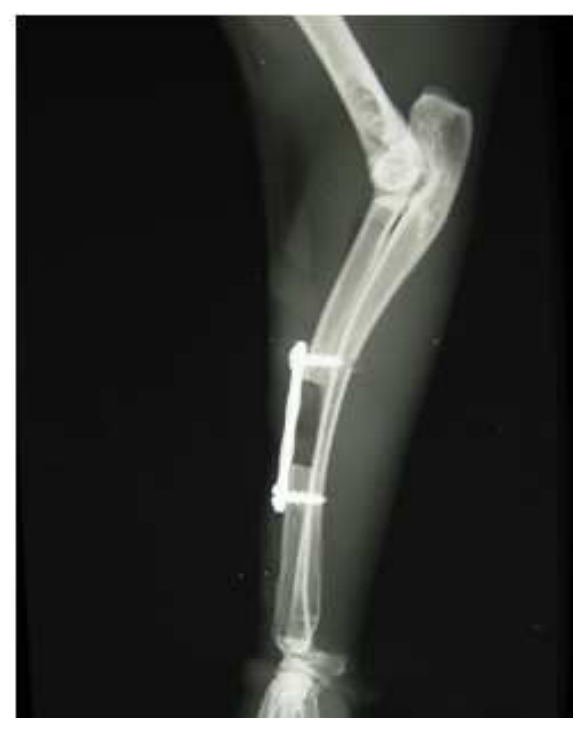

Fig. 1: Radiograph of Bone plate indicating no local reaction and dislocation after 30 days of fixation 


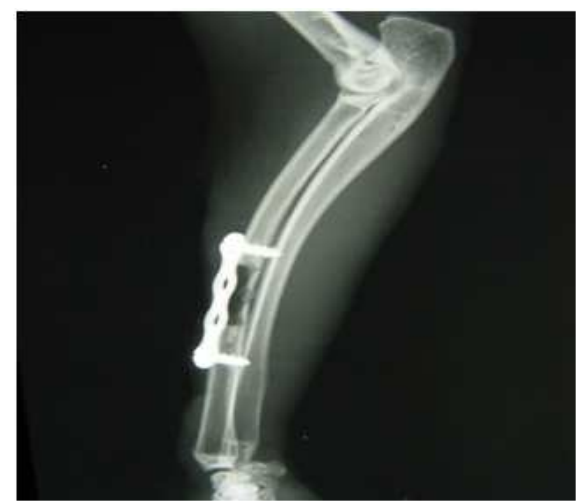

Fig. 2: Radiograph of Bone plate indicating local reaction internal callus formation at the both ends of radial bone after 60 days of fixation

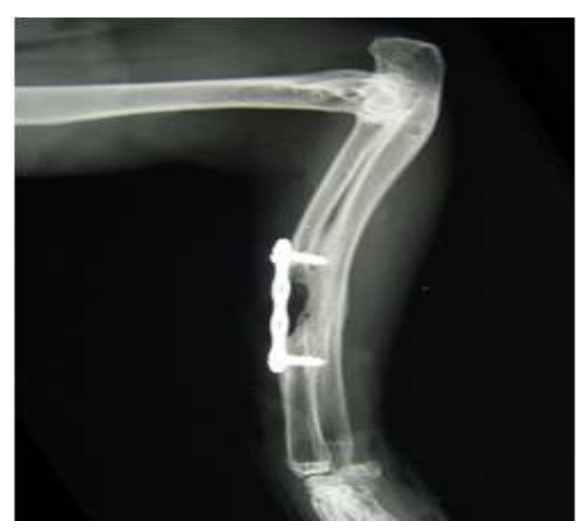

Fig. 3: Radiograph of Bone plate indicating local reaction of internal and Intermediate callus formation at the both ends of radial bone after 90 days of fixation

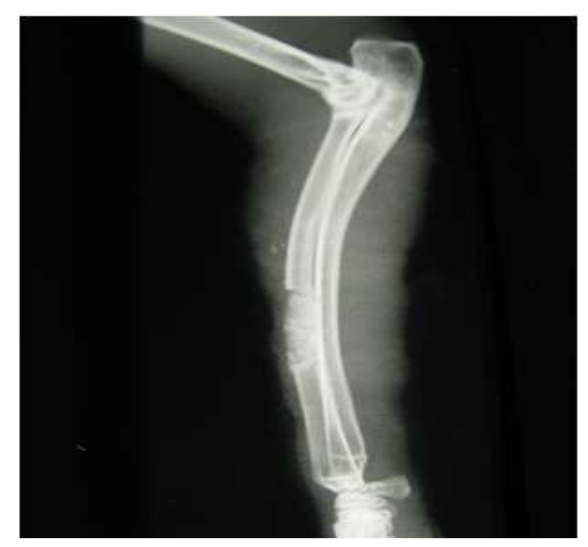

Fig. 4: Radiograph of the prehardened mixture of cements (TCPC and DCPC) Indicating no local reaction and loosening of implant after 30 days of fixation

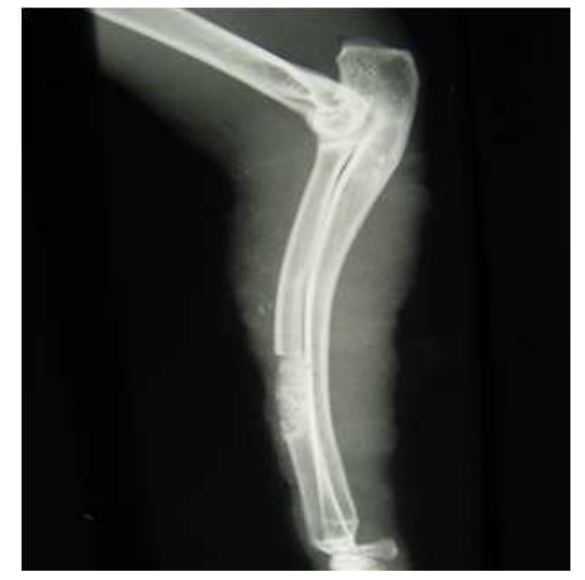

Fig. 5: Radiograph of the prehardened mixture of cements (TCPC and DCPC) Indicating no local reaction and loosening of implant with weakened Implant opacity after 60 days of fixation

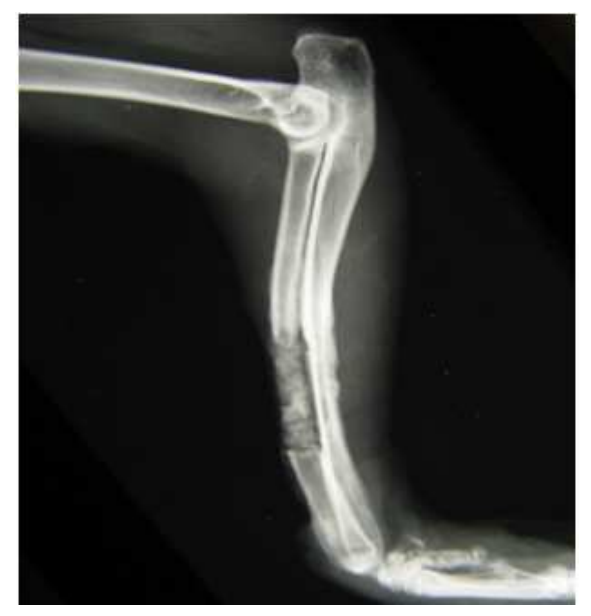

Fig. 6: Radiograph of the prehardened mixture of cements (TCPC and DCPC) Indicating host bone replacement with fading of umbral of the cement after90 days of fixation

\section{DISCUSSION}

An ideal biomaterial for bone tissue should be nonimmunogenic, biodegradable and highly effective osteoinduction and besides providing mechanical support ${ }^{[6]}$. The initial attachment and subsequent proliferation of osteogenic cells, as well as their ability to form bone are the most important factors affecting the success of a bone implant ${ }^{[7,8]}$. Application of these cements with correct biological activity the major changes revealed no sign of infection on the edges of 
each defect and There was no dislocation of implants in all groups ${ }^{[10-11]}$. Both groups permitted stabilization of the defected bones and maintenance of correct position. The new bone formation and the implant biodegradation in the bone defects could be clearly reflected by the gradually weakened umbral on the radiographs during the whole process ${ }^{[12-14]}$. The bone repair in group I was not as perfect as those in cement or group II samples, there was no dislocation of implants in all groups ${ }^{[15-17]}$. Lack of formation of external callus in both groups could be due to stable fracture and no movement of fractures segments ${ }^{[18-21]}$. Healing time was longer than normal, possibly due to large gap between two ends of fracture fragments in both groups ${ }^{[22-25]}$.

\section{CONCLUSION}

The present radiographic findings demonstrated the in our study, there was appreciatable osteointegration between cement and host defected bone without local soft tissue reaction which can be used to fill large gap for early stability and further stimulation for qualitative callus formation but the duration of the experiment was too short to investigate the complete resorption of the cement that used as an implant.

\section{ACKNOWLEDGEMENT}

The researchers wish to acknowledge the Faculty of Veterinary Medicine and University of Tehran Research Council for approval and financial support of this research.

\section{REFERENCES}

1. Damien, C.J. and J.R. Parson, 1991. Bone graft and bone graft substitute: A review of current technology and applications. Applied Biomatr., 2: 187-208. PMID: 10149083

2. Binderman, I. and N. Fin, 1990. Bone substitutesorganic inorganic and polymeric: Cell material interactions. In: CRC Handbook of Bioactive Ceramics, Yamamuro, T., L.L. Hench and J. Wilson-Hench (Eds.), Vol. 1, CRC Press, Boca Raton, FL., ISBN: 10: 0849332419, pp: 48.

3. Yoshimine, Y., M. Sumi, R. Isobe, H. Anan and K. Maeda, 1996. In vitro interaction between tetracalcium phosphate-base cement and calvarial estrogenic cells. Biomaterials, 17: 2241-2245. DOI: 10.1016/0142-9612(96)00045-2

4. Patrick, F., G. Laurent, C. Philippe F. Jacques and R. Nicole, 1998. Short term implantation effects of a DCPC-based calcium phosphate cement. Biomaterials, 19: 972.
5. Langstaff, S., M. Sayer, T.J. Smith and S.M. Pung, 2001. Resorbable bioceramics based on stabilized calcium phosphate. Part II: Evaluation of biological response. Biomaterials, 22: 135-150. PMID: 11101158

6. Ripamonti, U. and N. Duneas, 1996. Tissue engineering of bone by osteoinductive biomaterials. MRS Bull. Mater. Res. Soc., 21: 36-42. http://direct.bl.uk/bld/PlaceOrder.do?UIN=017065 798\&ETOC $=$ RN\& from $=$ searchengine

7. Shors, E.C., 1999. Coralline bone graft substitutes. Orthop. Clin. North Am., 30: 599-613. PMID: 10471765

8. Cornell, C.N., 1999. Osteoconductive materials and their role as substitutes for autogenous bone grafts. Orthop. Clin. North Am., 30: 591-598. PMID: 10471764

9. Brinker, W., 1990. Hand Book of Small Animal Orthopedics and Fracture Treatment. 2nd Edn., W.B. Saunder Company, 32.

10. Munting, E., A.A. Mirtchi and J. Lemaitre, 1993. Bone repair of defects filled with phosphocalcic hydraulic cement: An in vivo study. J. Mater. Sci. Med., 4: 337-344. DOI: 10.1007/BF00122290

11. Wang, X., J. Ma and Y. Wang et al., 2001. Structural Characterization of phosphorylated chitasan and their applications as effective additives of calcium phosphate cements. Biomaterials, 22: 2249.

12. Behairy, Y. and M. Jasty, 1999. Bone grafts and bone substitutes in hip and knee surgery. Orthop. Clin. North Am., 30: 665.

13. Covey, D.C. and D.G. Wright, 1992. Bone healing by induction: Clinical perspectives. Mil. Med., 158

14. Crisp, S., B.E. Kent amd B.G. Lewis et al., 1980. Glass-ionomer cement formulations. П. The synthesis of novel polycarboxylic Acids. J. Dent. Res., 59: 1066.

15. Yokoyama, A., S. Yamamoto and T. Kawasaki et al., 2002. Development of calcium phosphate cements using chitosan and citric acid for bone substitute materials. Biomaterials, 23: 1098.

16. Crisp, S. and A.D. Wilson, 1974. Reactions in glass ionomer cements: Ш. The precipitation reaction. J. Dent. Res., 53: 1422.

17. Jove Graham and Micheal Ries, 2003. Lisa pruitt, effect of bone porosity on the mechanical integrity of the bone cement interface. J. Bone Joint Surg. (Am.), 85: 1901-1908. http://www.ejbjs.org/cgi/content/abstract/85/10/19 01 
18. Maijer, R. and D.C. Smith, 1988. A comparison between zinc phosphate and glass ionomer cements in orthodontics. Am. J. Orthod. Dentofac. Orthop., 93: 273-279.

http://www.ncbi.nlm.nih.gov/pubmed/3281438.

19. Ritter, M.A, S.A. Herbst and E.M. keating et al., 1994. Radiolucency at the bone-cement interface in total knee replacement. The effects of bone-surface preparation and cement technique. J. Bone Joint Surg. $\quad$ (Am.), 76: 60-65. http://www.ncbi.nlm.nih.gov/pubmed/8288666.

20. Saunders, J.E., 2006. Alloplastic bone cements in otologic surgery: Long term follow and lessons learned. Otolaryngol. Head Neck Surg., 135: 280-285. http://www.ncbi.nlm.nih.gov/pubmed/16890083.

21. Seeherman, H.J., K. Azari and S. Bidic et al., 2006. $\mathrm{Rh}$ BMP-2 delivered in a calcium phosphate cement accelerates bridging of critical-Sized defects in rabbit radii. J. Bone Joint Surg. (Am.), 88: 1553-1565. DOI: 10.2106/JBJS.E.01006

22. Sharifi, D., G.H.R. Abedi and F. Sasani et al., 2001. Gross and histomorphological study of bone cement and bone graft in dog. http://www.vin.com/VINDBPub/SearchPB/Procee dings/PR05000/PR00536.htm
23. Wang, E.A., V. Rosen and P. Cordes et al., 1988. Purification and characterization of other distinct bone-inducing factors. Proc. Natl. Acad. Sci. USA., 85: 9484-9498. http://www.pnas.org/content/85/24/9484.abstract

24. Wu, W., W. Yang, D. Zhou, J. Ma and B. Xiao, 2006. A study on alpha-tricalcium phosphate bone cement carbon fiber-reinforced. Sheng Wu Yi Xue Gong Cheng Xue Za Zhi, 23: 569-572. http://www.ncbi.nlm.nih.gov/pubmed/16856391.

25. Yasko, A.W. and J.M. Lane et al., 1992. The healing of Segmental bone defects, induced by recombinant human bone morphogenetic protein (rh BMP -2). A radiographic, histological and biomechanical study in rats. J. Bone Joint Surg. (Am.), 74-A: 652-670. http://www.ejbjs.org/cgi/content/abstract/74/5/659. 